\title{
Economic Growth, Investment, Population Growth and Unemployment in Ethiopia
}

\author{
Betgilu Oshora ${ }^{1, *}$, Tiblets Nguse $^{1}$, Maria Fekete-Farkas², Zoltan Zeman ${ }^{2}$ \\ ${ }^{1}$ Doctoral School of Economic and Regional Science, Szent István University, 1 Páter K. Str., Gödöllő, 2100, Hungary \\ ${ }^{2}$ Faculty of Economics and Social Sciences, Szent István University 1 Páter K. Str., Gödöllö, 2100, Hungary
}

\begin{abstract}
The study examines the correlation between economic growth, investment, population growth and unemployment in Ethiopia. For the purposes of this study, secondary time series data collected from the National Bank of Ethiopia, IMF and World Bank databases were used. The study extracts the perceived relationship between the variables through principal component (PCA) analysis. Both the Kaiser-Meyer-Olkin measure of sampling adequacy and Bartlett's test of sphericity were used to determine the appropriateness of the dataset for PCA. The results revealed that an increase in unemployment is positively correlated, but in the opposite direction to economic growth, investment, total population and the working-age population. On top of the rapid spread of COVID-19, the present protests as a result of the political instability and ethnic problems across the country will lead to an increase in unemployment and the loss of many lives. Policymakers therefore need to emphasize and assure an increase in economic growth and investment in order to create more jobs in line with the increasing demand for jobs, particularly by young people. Moreover, the government must address the ongoing ethnic problems and political instability before it hits the economy adversely.
\end{abstract}

Keywords: COVID-19; Ethiopia; economic growth; population growth, investment, unemployment

\section{Introduction}

Inclusive and sustainable economic growth is very crucial for the success of the implementation of the Sustainable Development Goals (SDGs). Although the global economy continues to grow, it is doing so at a slower rate and unemployment is growing. Hence there is a need for more progress in creating more work that is decent for all. One fifth of the world's youth were not in education, employment or training [1]. Decent work is crucial to achieving inclusive economic growth, since such work is more than just a source of income and social protection. Also, across all country income groups, young people aged 15-24 years' experience a higher unemployment rate than the rest of the working-age population [2]. For instance, of the 5\% global unemployed in 2018, youth were three times more likely to be unemployed than adults [1]. Furthermore, the study by [3] shows that unemployment can result in depression, which is a major public health problem among unemployed young adults in Ethiopia. Moreover, it is widely recognized that youth employment and economic empowerment are essential components of strong societal foundations [4].

According to [5], the unemployed are people of working age who are without work, are available for work, and have taken specific steps to find work. At present, unemployment remains unacceptably high at the global level and the majority of employed people are in informal employment, with many of them living in extreme poverty. For instance, according to the 2015 Employment, Skills and Human Capital Global Challenge Insight Report, more than 200 million people are out of a job globally and the numbers are forecasted to rise to 215 million jobseekers by 2018. In order to match the growing labour force, it is estimated that nearly 42 million new jobs need to be created annually [6]. In 2018, out of the 5.7 billion working-age people, i.e. 15 years or older, 3.3 billion people were in employment and 172 million unemployed [7]. Moreover, 2 billion people make their living in the informal economy at the global level according to [8] and almost $77 \%$ of the world's young workers are in informal jobs, compared with around $60 \%$ of adult workers [9].

The results of many empirical studies show that workers in the informal economy face a higher risk of poverty than those in the formal economy. For instance, in emerging and developing countries, more than 300 million

\footnotetext{
* Corresponding Author: betgilu2002@gmail.com
} 
workers live in extreme poverty $(<\$ 1.90 /$ day). Furthermore, unemployment in developing countries is expected to increase by half a million per year in both 2018 and 2019, with the unemployment rate remaining at around $5.3 \%$ [10]. Out of 1.3 billion people living in Africa, 764 million people are aged 15 years or older, of which $4.3 \%$ of those of working-age are unemployed. This may seem like a very small fraction compared with the $60 \%$ who are employed, but many people have no choice but to take up informal jobs of poor quality in order to meet their basic needs and escape poverty. Being in employment does not always guarantee a decent living. For instance, in 2018, more than one quarter of workers in low- and middle-income countries were living in extreme or moderate poverty [7].

In contrast to the issue of high global unemployment, [6] shows that employers continue to complain about the difficulties they face in finding talent for vacant positions, pointing to a mismatch between available and needed skills. It is the shared opinion of the authors that it is important to recognize that this issue is a common and serious problem mainly in developing countries where the educational curriculums for many disciplines have a theoretical orientation rather than a practical one. This problem is also reflected at the university level, which exacerbates the problem. In addition, industries also do not allow students that live close by to gain practical experience.

According to [11], young people are three times as likely as adults (25 years and older) to be unemployed. At the global level there are approximately 1.3 billion young people between the ages of 15 and 24 , of which about 68 million are unemployed. Moreover, about 126 million (30\%) of employed youth remain in extreme or moderate poverty despite having a job. In addition, over three-quarters of young workers are engaged in informal employment. Similarly, the ILO (2015) report on five facts about the informal economy in Africa shows that the quality of jobs is questionable and nearly 8 out of 10 employed persons in Sub-Saharan Africa were in vulnerable forms of employment. This indicates that being employed does not guarantee young people a decent life. For this reason decent work is given due attention in the United Nations 2030 Agenda as a specific goal (SDG 8), with many targets [12]. The sub-Saharan region needs to raise growth to create the additional 20 million jobs per year needed to absorb new entrants to the labour markets. More growth, more jobs policies are needed to create more jobs in the coming years [13].

The issue of unemployment has become a severe challenge for all African countries, regardless of their different socio-economic development. People often do not have a choice with regards to their employment due to the lack of available opportunities and are therefore underemployed, i.e. their job is not their profession or is irrelevant to their field of study. Ethiopia is the second most populous nation in Africa after Nigeria, and the fastest growing economy in the region. The economy experienced strong, broad-based growth averaging $9.9 \%$ a year from 2007/08 to 2017/18, compared to a regional average of 5.4\%. However, it is also one of the poorest, with a per capita income of $\$ 790$ [14]. Despite reducing the extreme poverty rate from about $46 \%$ in 1995 to $23.5 \%$ in 2016, Ethiopia still has more than 25 million people living in poverty [15].

Despite the country's strong economic growth over the last 15 years, statistical data for 2015 on the unemployment rate in urban areas shows it to be $17.5 \%$, which is an enormous challenge when it comes to inclusive economic development [16]. In Ethiopia, the lack of economic opportunities is the primary driver of youth frustration, with more than $25 \%$ youth unemployment. However, the number of underemployed youth is likely to be much higher [17]. More importantly, Fantaw \& Bitga also state that young people claim that their voices are not being heard when it comes to community-level decision-making processes, which will drive unrest and instability in Ethiopia over the next decade and beyond. Furthermore, the current political uncertainty, plagues of locusts and COVID-19 pandemic will create a serious challenge for economic growth and will contribute to increasing numbers of people living below the poverty line and requiring humanitarian assistance. At present, different countries around the world are experiencing demographic changes, unemployment and the shutdown of economic activities to save human lives [18]. Due to the nature of globalization and economic interconnectedness, [19] states that it is difficult to mitigate the pandemic.

The Federal Democratic Republic of Ethiopia has developed a comprehensive job creation strategy to reduce unemployment in a market that sees about 2 million new workforce entrants each year and which aims to create 14 million jobs by 2025 [20]. However, the rapid spread of COVID-19 will harm the implementation of the strategy unless a new strategy can be put in place that minimizes the risks to the implementation of the wide ranging and comprehensive strategy. Moreover, the lockdown due to the pandemic is expected to hurt companies that hire the majority of employees, in particular small private companies. As a result, it will more likely hurt the $25 \%$ of the population already living in extreme poverty and whose income, even before the pandemic, was more dependent on daily labour and employment in informal jobs. The main aim of this study is to examine the status of unemployment and COVID-19 in Ethiopia and more specifically to:

1. Explore the correlation between unemployment, economic growth, investment, total population and the working-age population; 
2. Examine the current status of the COVID-19 pandemic and its effect on employment.

\subsection{Conceptual framework}

The conceptual framework is depicted in Figure 1. This takes into account four independent variables for examining the correlation between the variables. An increase in the working-age population will increase the numbers joining the labour market. As a result, unless job creation increases in line with the increase in numbers seeking employment, unemployment will rise. In contrast, an increase in real GDP growth rate and investment are likely to contribute positively to the reduction of unemployment. Unfortunately, the current COVID-19 pandemic will enhance the existing rate of unemployment due to lockdown and stay-at-home measures.

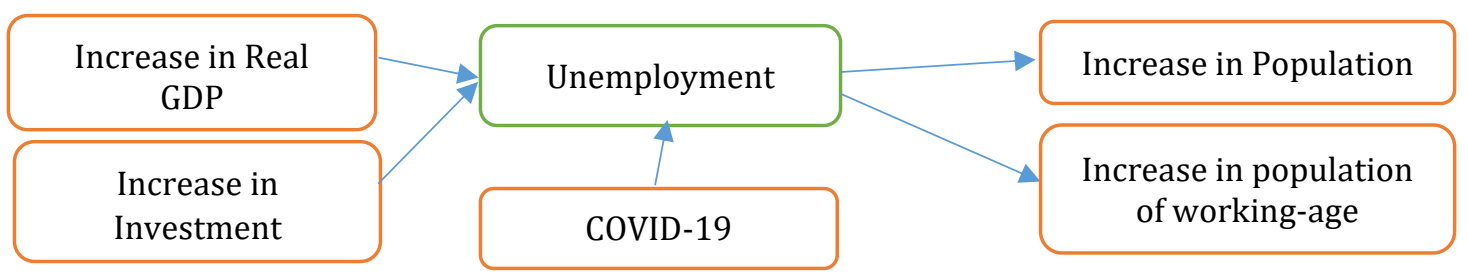

Figure 1. Conceptual Framework

Source: Authors.

\section{Methodology}

For the purposes of this study, we extracted 20-year time-series data from 2000 - 2019 from the National Bank of Ethiopia annual reports to examine the correlation between the variables under study, such as unemployment, total population growth, working-age population growth, investment and economic growth. To process the collected data, a multivariate statistical analysis, in the form of Principal Component Analysis (PCA), was applied using Minitab software to examine the relationships and significance in and between the variables. To verify that the dataset is suitable for PCA, Bartlett's test of sphericity and the Kaiser-Meyer-Olkin (KMO) were applied. Moreover, the eigenvalue rule was applied to determine the number of components to be considered for further investigation.

To support the results, we collected secondary data from the IMF, WHO and World Bank databases for descriptive analysis. This involved examining the trends for the variables over the past few decades and presenting them with the use of MSExcel spreadsheets. Furthermore, to develop a comprehensive understanding of the subject, empirical evidence was sought from different reports, websites, the Web of Science, Google Scholar, Research Gates, Academic.edu and Mendeley, under keywords like COVID-19, Ethiopia, growth and unemployment.

\section{Results and Discussion}

\subsection{Descriptive (trend) analysis}

In this section, the trends for the variables are presented and compared with other countries on the same continent. The main aim of reflecting the trend of the determinants and the status of the dependent variable is to triangulate the results obtained from the statistical methods using factor analysis.

As is evident in Figure 2 below, investment and real GDP growth for the country over the last two decades have been incremental, with exception to the sharp decline in real GDP growth rate in 2003. Despite the promising increase in economic growth and investment across the country, the unemployment rate remains 2 percent on average above over the same decades. This is mainly due to the increase in the population and of the working-age population joining the labour market, as illustrated in Figure 3 below. Over the last two decades, the total population and working-age population increased by more than 2 million and 1.3 million on average, respectively. As a result, with too few jobs available, the annual increase in the working-age population joining the labour market, plus the existing unemployed, is a major challenge for the government. 


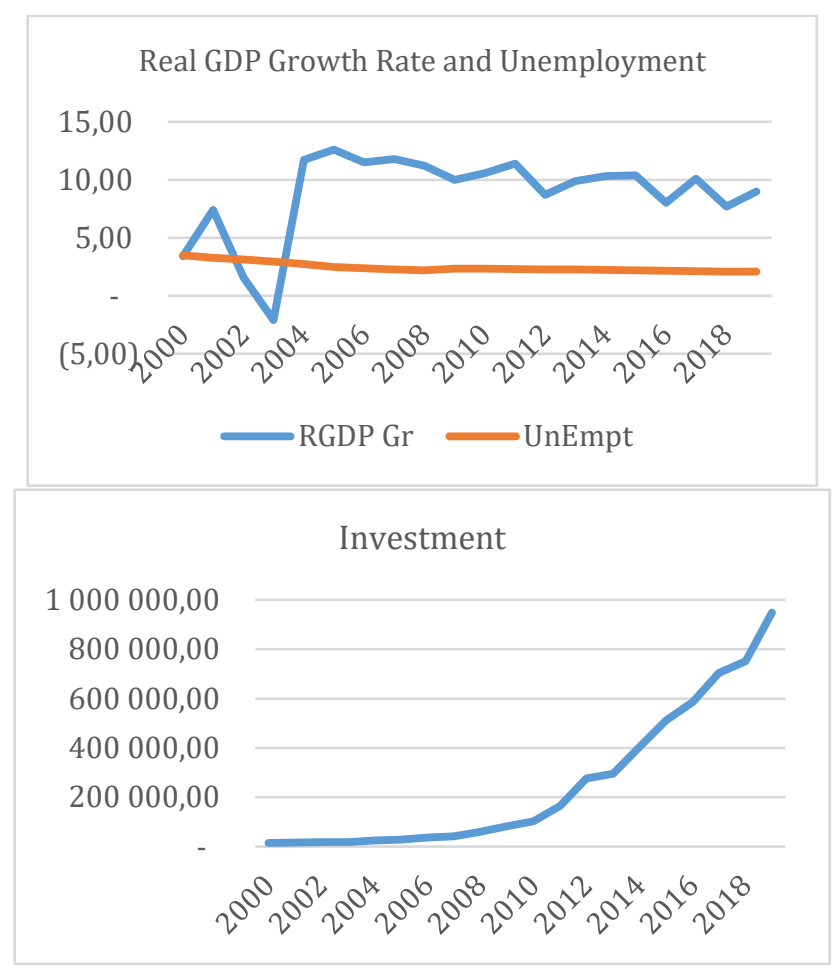

Figure 2. Economic growth, unemployment and investment trends

Source: Authors.

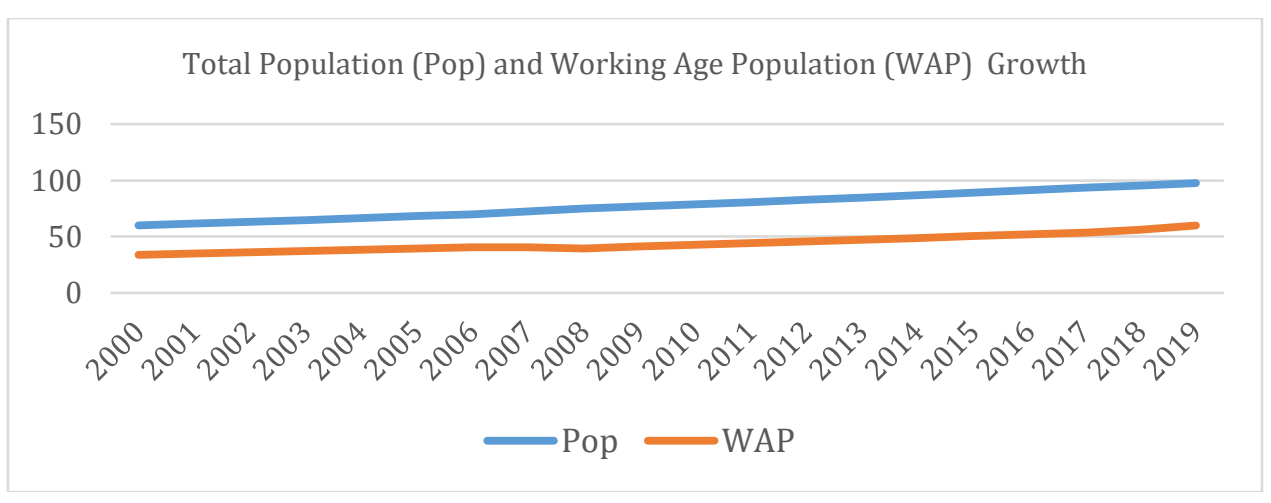

Figure 3. Total population and working-age population growth.

Source: Authors.

As is evident, the Ethiopian economy has been growing at a remarkable rate for the last few years. However, it is important to examine how that growth has translated into more jobs that are of a better quality and are inclusive. The statistical figures show that more than $70 \%$ of Ethiopians are under 30 years of age, with urban youth unemployment standing at $22 \%$ compared to an overall unemployment rate of $17 \%$. Moreover, more than a quarter of all urban jobs are informal [21]. Given the large number of university and college graduates, it is a challenge for a developing country like Ethiopia to create and maintain productive employment. For instance, the authors of [22] reveal that educated unemployed youth are at the epicentre of the current protests, complaining about the fact that they have university degrees but can only find employment 'breaking cobblestones' for pedestrians sidewalks. There is therefore a need for a clearer understanding of the remaining challenges based on further empirical analysis to provide all stakeholders with urgent guidance on how to achieve SDG 8.

Moreover, as depicted in Figure 4 below, Ethiopia is also a country with the fastest population growth rate on average in sub-Saharan Africa, among low-income countries, and the world. This shows that unless employment opportunities increase equally, unemployment is expected to increase during the next few decades, thereby bringing into doubt the implementation and attainability of the SDGs. This will be exacerbated by the current COVID-19 pandemic, which will cause significant harm the global economy and consequently the realization of the SDGs. According to [23], COVID-19 will be a real challenge for the UN with regards to its efforts to eradicate poverty (SDG1) by 2030 and a major challenge for developing countries because the number of people living 
under the three poverty lines is estimated to increase to between 420-580 million. Therefore, even though no one knows how long the pandemic will last, the achievement of the 2030 Agenda, and in particular, no poverty and zero hunger (SDG 1) and decent work for all (SDG8), is under considerable threat. The impact of COVID-19 will more likely hit the poorest regions, especially SSA and South Asia, where the potential new poor, i.e. under the US\$1.90/day and US\$3.20/day poverty lines, are estimated to represent $80-85 \%$ of the total poor [23].

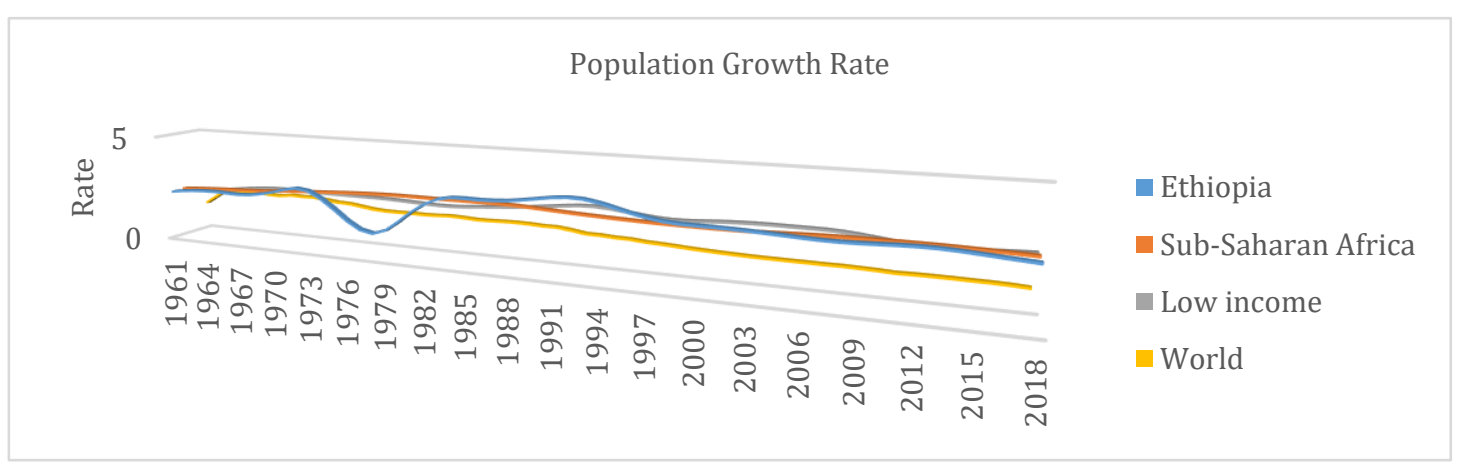

Figure 4. Ethiopian population growth compared with other populations

Source: Authors.

A comparison of the economic growth of the country with East Africa and sub-Saharan countries, reveals that Ethiopia is one of the fastest growing economies on the continent (see Figure 5 below). Like the global economy, lockdown measures due to COVID-19 are expected to have a negative impact on the country's economic growth in the coming years.

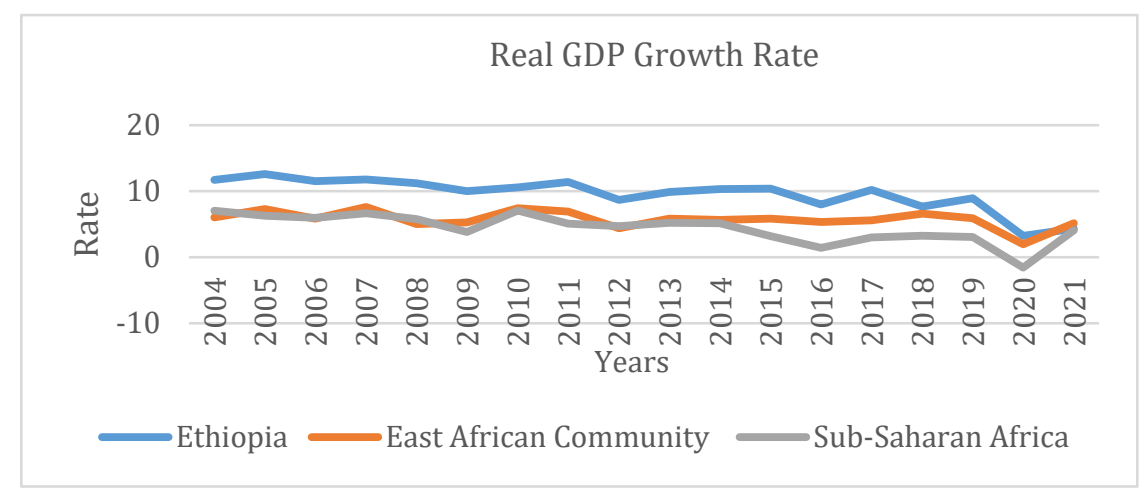

Figure 5. Economic growth compared with SSA and East Africa

Source: Authors.

\subsection{Status of COVID-19 pandemic in Ethiopia}

According to recent Worldometer data, Ethiopia is the second most populous nation in Africa after Nigeria and is ranked twelfth in the world, with a total population of 115,260,592 as of Wednesday, 5 August 2020. Moreover, the population is growing more rapidly than expected, which is evident when the numbers are compared to the UN's mid-year estimated figure for the total population of 114,963,588 [34]. On 13 March 2020, Ethiopia joined the rest of the world by reporting the first case of COVID-19 and immediately called for several restrictions on human mobility in a bid to contain the pandemic.

The Ministry of Health (MOH) and Ethiopian Public Health Institute (EPHI) in collaboration with partners have intensified response efforts to prevent the spread and severity of the COVID-19 pandemic in Ethiopia [24]. Since the first case was reported in Ethiopia on 13 March 2020, the pandemic has spread rapidly throughout the country. As of writing this article, there were a total of 18,706 confirmed COVID-19 cases and 310 deaths [35]. As depicted in Figure 6 and 7 below, the number of new cases and deaths is increasing exponentially, in particular over the last month. In the last month, new cases and deaths accounted for $69 \%$ and $67 \%$ of the total cases, respectively. Moreover, despite the positive aspects of the country's early response, its young population, low population density in rural areas, and experience with handling large scale crises, there are also negative aspects such as a weak health system, poor nutritional status, lack of access to proper hygiene and sanitation and densely populated urban areas [25]. 
Authorities have closed borders, closed schools, ordered the shuttering of nightclubs and entertainment outlets, announced social distancing measures, and called in retired and in-training medical personnel. In addition, all people entering Ethiopia from another country are subject to a mandatory 14-day quarantine at designated hotels at the traveller's expense. The authorities postponed elections, which were scheduled for 29 August, for as long as 12 months. On 8 April, the Prime Minister declared a state of emergency under Article 93 of the constitution, which allows it to impose more stringent measures. The measures put in place to ease the spread of COVID-19 are pushing millions of people in Ethiopia into severe hunger and unemployment. Inactive economic activity can lead to unemployment, loss of wages, and consequently, loss of income. Yet now, the federal government and many humanitarian organizations are distributing food to ease the pain of the lockdown imposed to stop the spread of the coronavirus pandemic. However, this is unsustainable for a long period, leading to questions about the imposed measures.

Food prices have increased dramatically because of movement restrictions and border closures. However, according to [26], "the impact of COVID-19 on food insecurity is much weaker compared to that in upper-middleincome countries". Globally, food insecurity is becoming a very serious issue, challenging the economic development of the world. Of the 7.6 billion people that make up the world's population, $17 \%$ and $9 \%$ are living under moderate and severe food insecurity. This situation is even more severe on the African continent, where, according to FAO data [27], of the total population of Africa, $31 \%$ and $21 \%$ are living in moderate and severe food insecurity. Highly crowded urban populations (particularly in capital city Addis Ababa), limited medicinal and pharmaceutical products, and weak economies that are unable to sustain health and lockdown costs, are just a few of the reasons that will make the country more vulnerable. For instance, the economic growth of Ethiopia is expected to fall to a 17 -year low of $3.2 \%$ this year- down from $9 \%$ in 2019 [28].

Despite the hopes of Ethiopians [29] about democracy following the election of Abiy Ahmed as prime minister in 2018, hundreds of people have been killed in protests across the country over the last two years. The increasing intensity of the protests and demonstrations, particularly in the Oromia region and in Addis Ababa will enhance the spread of the pandemic. Moreover, failure to adhere to stay-at-home and physical distancing measures, the extreme poverty in which a large part of the population lives, and other preventive measures to minimize the risk of spread remain a challenge for the government. The shortage of hospital beds, the inadequacy of quarantine sites, the shortage of testing facilities, Personal Protective Equipment (PPE) for health professionals, the challenges of the track and trace system, the shortage of health professionals and so on are also hurdles that need to be jumped. The lack of health professionals and poorly equipped facilities relative to the total population will influence the country's ability to combat the pandemic [30]. All the stakeholders therefore need to practice all of the imposed preventive measure to protect themselves and those around them in order to stay healthy.

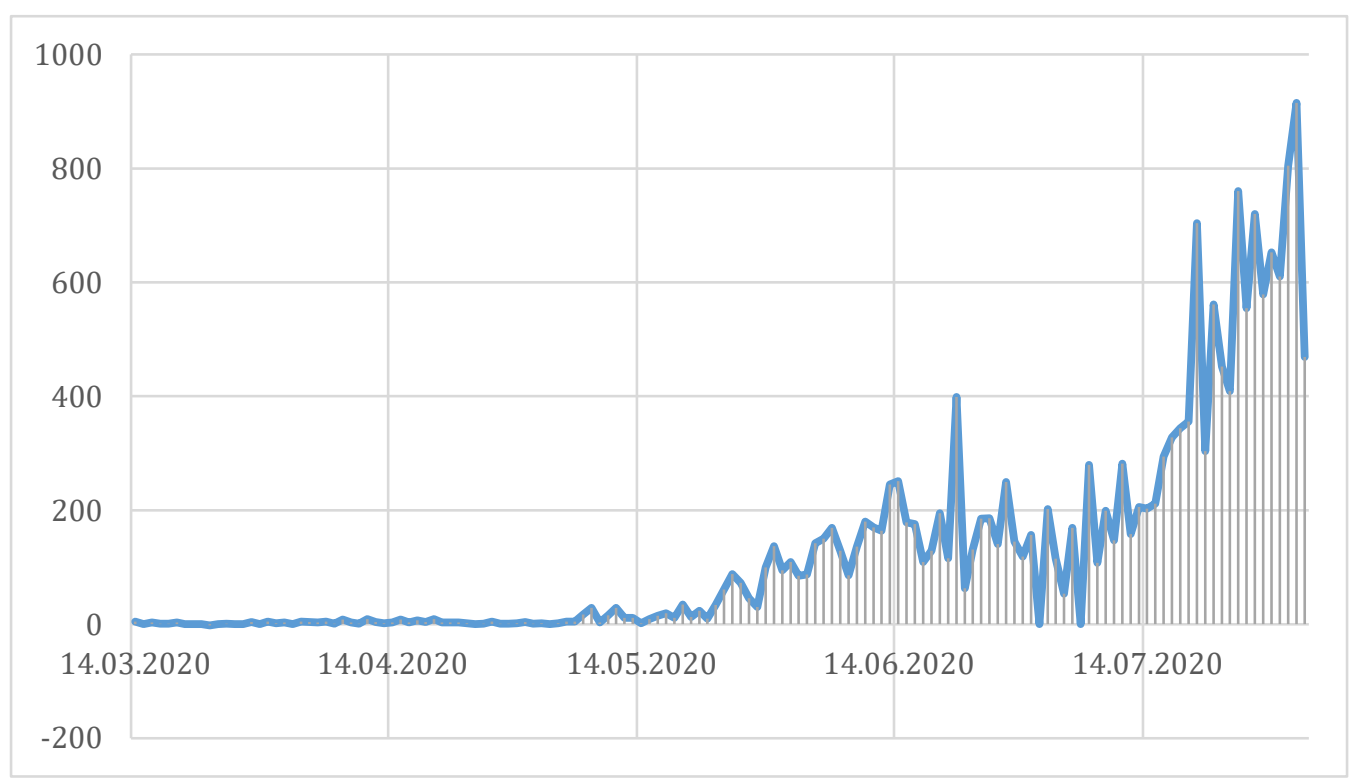

Figure 6. COVID-19 daily new cases in Ethiopia

Source: Authors. 


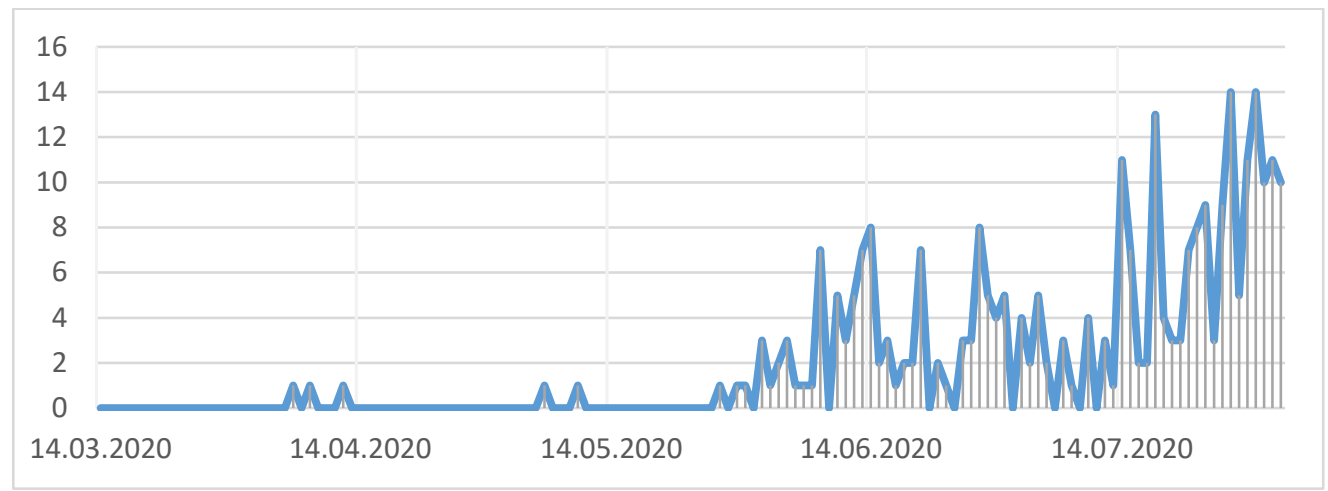

Figure 7. COVID-19 daily deaths in Ethiopia

Source: Authors.

As is the case in other countries, the increasing public health crisis, falling commodity prices and mitigation measures are having a significant effect on the economic activity of the country. Informal sectors are highly exposed to risk due to the impact of COVID-19, more so than other sectors despite hiring more daily wage earners. Hence the majority of wage workers will be highly exposed to the risk of food insecurity. For this reason, the mitigation measures are unlikely to be effective in the absence of sufficient government support to convince people to stay at home. Due to the lack of testing capacity to detect and quarantine people carrying COVID-19, we are highly concerned about the capacity of the country to deal with this outbreak. Taking into account that the majority of people are living under severe and moderate poverty, it will be difficult to implement travel and movement restrictions, lockdowns, border closures, bans on public gatherings, school closures, and so on. The government must therefore ensure that if stay-at-home measures are to be effective in combating the pandemic, they must not be at the expense of the human rights.

\subsection{Testing of data adequacy}

We conducted two tests to measure sampling adequacy in order to determine the factorability of the whole matrix. The two tests were Bartlett's test of sphericity and the Kaiser-Meyer-Olkin test. Accordingly, a measure of sampling adequacy was conducted by testing KMO for the set of variables included in the analysis. The test result was 0.706 , which, when compared with the minimum requirement of 0.50 as per standard $[31,32]$, implies that the data is appropriate for PCA. The result of Bartlett's test of sphericity was significant $(p<0.005, p=0.000)$. This, in combination with the fact that the KMO measure was greater than 0.5 , means that we can conclude that the data is appropriate for PCA and factor analysis (see Table 1 below).

Based on the results, it is appropriate to proceed with PCA to examine the correlation between unemployment and the other variables, namely total population growth, investment, economic growth and working-age population growth.

Table 1. KMO and Bartlett's test for data appropriateness

\begin{tabular}{|c|c|c|}
\hline \multicolumn{2}{|c|}{ Kaiser-Meyer-Olkin measure of sampling adequacy. } & .706 \\
\hline \multirow{3}{*}{$\begin{array}{l}\text { Bartlett's test of } \\
\text { sphericity }\end{array}$} & Approx. Chi-Square & 153.308 \\
\hline & Df & 10 \\
\hline & Sig. & .000 \\
\hline
\end{tabular}

Source: Authors.

It is also important to check the variability of the data and to know whether there is a strong relationship between the variable and the component in isolation, which can be achieved using a component matrix. Since all the variables in the first component of the correlation matrix are greater than 0.3 , we can conclude that the variables are strongly correlated. However, in the second component, only three variables (investment, unemployment and real GDP growth rate) are correlated with the component. Therefore, as can be seen in Table 2 below, total population, working-age population, investment, unemployment and real GDP growth rate strongly correlate in the component. In the case of the second component, the real GDP growth rate strongly correlated with the component, followed by investment and unemployment. 
Table 2. Extracted component matrix

\begin{tabular}{|l|c|c|}
\hline & \multicolumn{2}{|l|}{ Component } \\
\cline { 2 - 3 } & 1 & 2 \\
\hline Population total, in millions (mid-year population) & .983 & \\
Working-age population (in millions ) & .972 & \\
Investment & .895 & .398 \\
Unemployment & -.891 & .325 \\
Real GDP growth rate (in \%) & .472 & -.855 \\
\hline
\end{tabular}

Source: Authors (Extraction Method: Principal Component Analysis).

\subsection{Principal Component Analysis}

After testing the suitability of the data for PCA, we conducted dimension reduction by ignoring the less significant components based on Kaiser's criterion, or the eigenvalue rule (only factors with an eigenvalue of 1.0 or more are retained for further investigation). Accordingly, as can be seen in Table 3 below, we retained only the first two components for further investigation (eigenvalues were 3.731 and 1.059, respectively). We ignored the remaining three components, for which the eigenvalue was less than 1.0, which means that the component has less information than a single variable. The first two artificial components explain $95.804 \%$ of the total variance, which means that we could keep $95.804 \%$ of the information after the dimension reduction.

Table 3. Total variance explained by the components

\begin{tabular}{|c|c|c|c|c|c|c|c|c|c|}
\hline \multirow[t]{2}{*}{$\begin{array}{l}\text { Comp } \\
\text { onent }\end{array}$} & \multicolumn{3}{|c|}{ Initial eigenvalues } & \multicolumn{3}{|c|}{$\begin{array}{l}\text { Extraction sums of squared } \\
\text { loadings }\end{array}$} & \multicolumn{3}{|c|}{$\begin{array}{l}\text { Rotation sums of squared } \\
\text { loadings }\end{array}$} \\
\hline & Total & $\begin{array}{c}\% \text { of } \\
\text { Variance }\end{array}$ & $\begin{array}{c}\text { Cumulativ } \\
\text { e } \%\end{array}$ & Total & $\begin{array}{c}\% \text { of } \\
\text { Variance }\end{array}$ & $\begin{array}{l}\text { Cumulat } \\
\text { ive } \%\end{array}$ & Total & $\begin{array}{c}\% \text { of } \\
\text { Variance }\end{array}$ & $\begin{array}{l}\text { Cumul } \\
\text { ative \% }\end{array}$ \\
\hline 1 & 3.731 & 74.617 & 74.617 & 3.731 & 74.617 & 74.617 & 3.254 & 65.089 & 65.089 \\
\hline 2 & 1.059 & 21.187 & 95.804 & 1.059 & 21.187 & 95.804 & 1.536 & 30.715 & 95.804 \\
\hline 3 & .183 & 3.655 & 99.459 & & & & & & \\
\hline 4 & .021 & .419 & 99.878 & & & & & & \\
\hline 5 & .006 & .122 & 100.000 & & & & & & \\
\hline
\end{tabular}

Source: Authors (Extraction Method: Principal Component Analysis).

In order to decide which components should be retained for further investigation, [33] also suggests finding the point at which the shape of the curve changes direction and becomes horizontal and to then retain all the components above the elbow, or break in the plot, because these components contribute the most to the explanation of the variance in the dataset. Hence, by using the Cattel scree plot test, the first two components explain much more of the variance than the remaining components; we, therefore, extracted two components only for further investigation. Alternatively, the remaining principal components account for a very small proportion of the variability (close to zero) and are probably unimportant. The scree test also supports the decision made to retain the first two components by using the eigenvalue rule as depicted.

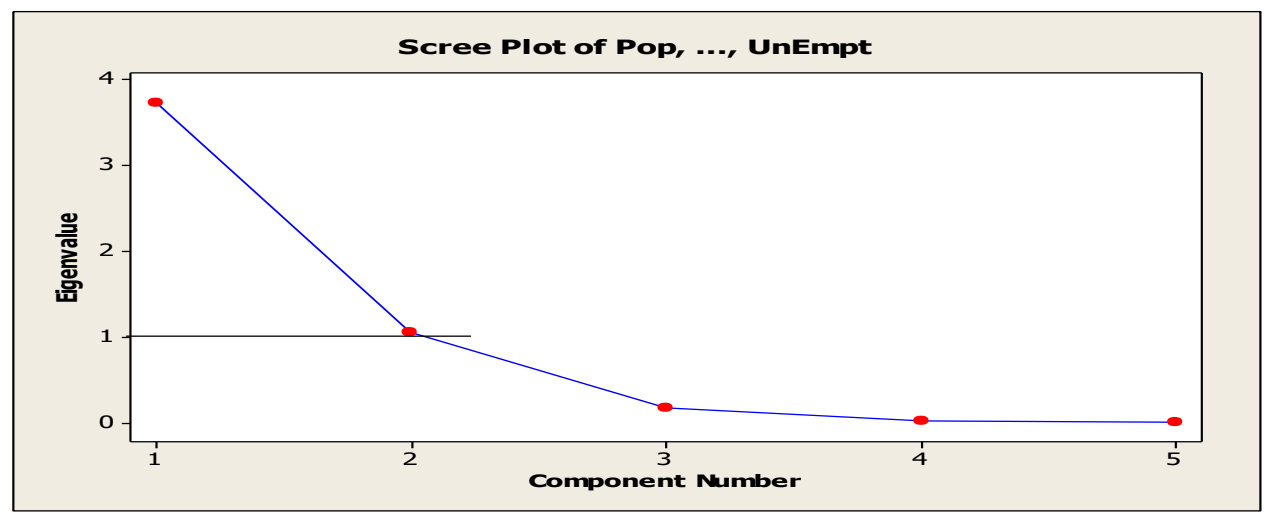

Figure 8. Scree plot for principal component analysist

Source: Authors. 
The visualization of the loading plot in Figure 9 shows that the first component of the variables working-age population, total population and investment are positively correlated in the same direction, but correlated in the opposite direction with unemployment. In the second component, the variable real GDP growth rate is a lonely variable, independent of any other variables.

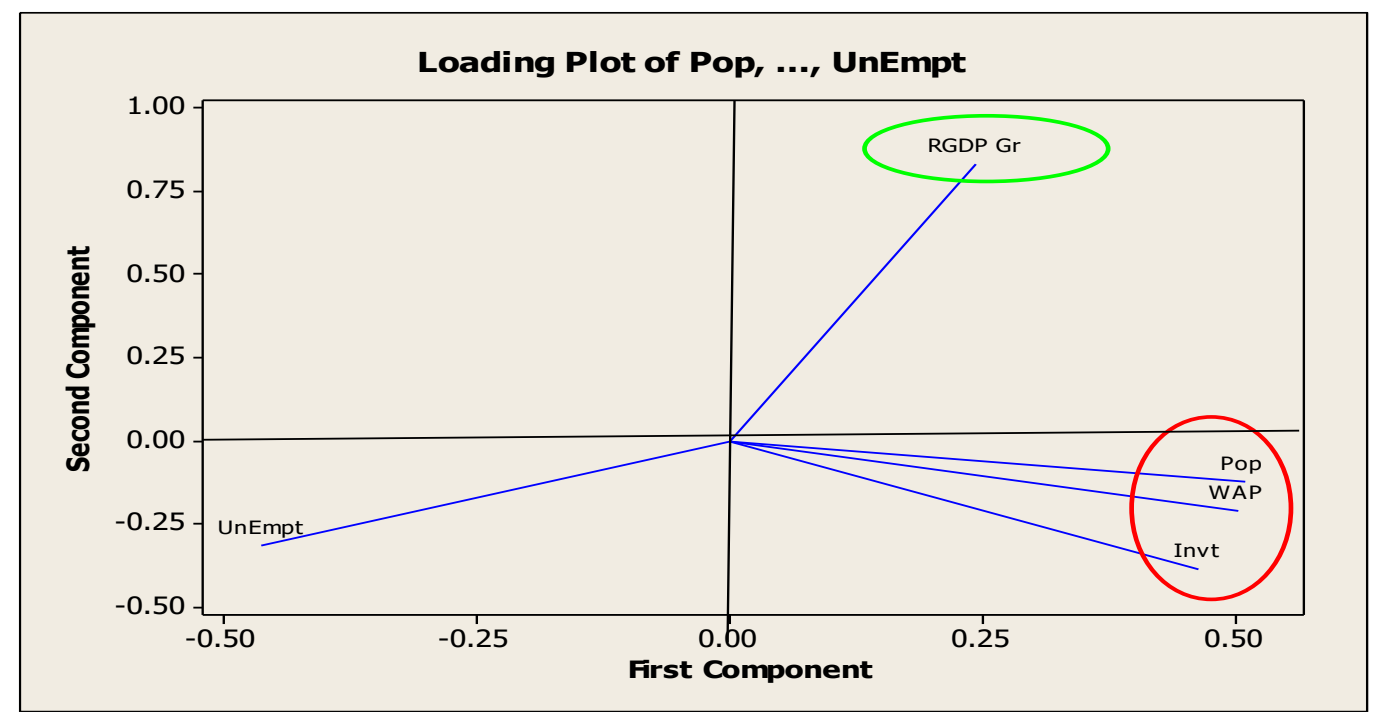

Figure 9. Loading plot for principal component analysis

Source: Authors.

\section{Conclusion}

At present, unemployment, in particular among those aged 15-24 years, remains a global challenge for the achievement of inclusive economic growth. Different findings reveal that the majority of employed people are in informal employment and many of them live in extreme poverty. This study aimed to examine the correlation between unemployment and selected independent variables based on time series data from 2000-2019. The results showed that unemployment is positively correlated but in the opposite direction to total population, working-age population, investment and economic growth. By looking at trend data, it is clear to see that despite economic growth and investment, unemployment is increasing. Similarly, the increase in the total population and the working-age population also create an increase in unemployment. Policymakers must therefore come up with a strategy that increases economic growth and investment and creates job opportunities, in particular for the young population. Within this context and that of population growth, it is possibly advisable to set a maximum birth limit to reduce the highly increasing population growth rate.

Beyond this, the COVID-19 pandemic is expected to result in companies failing and going into bankruptcy, resulting in reduced economic growth and rising unemployment. This will be exacerbated by falling investment due to the current political instability, ethnic problems and protests, which in all likelihood could lead to social unrest and instability, contributing to a further increase in unemployment. Policymakers, the government in particular, must call for solidarity to combat the pandemic and put forward possible remedies to save the lives of the most vulnerable people during this period since staying at home without access to food is not possible for them. On the other hand, the federal government must give due attention to mitigating the rapid spread of COVID19 and not being part of creating another pandemic, which may cause further political instability and ethnic problems.

\section{References}

1. UN. Secretary-General, Progress towards the Sustainable Development Goals: report of the SecretaryGeneral [online]. Available at: https://digitallibrary.un.org/record/3810131

2. International Labour Organizaton, Time to Act for SDG 8: Integrating Decent Work, Sustained Growth and Environmental Integrity $\quad$ Aonline]. https://www.ilo.org/global/publications/books/WCMS_712685/lang--en/index.htm (2019) 
3. H. Mokona, K. Yohannes, G. Ayano, Youth unemployment and mental health: Prevalence and associated factors of depression among unemployed young adults in Gedeo zone, Southern Ethiopia. International Journal of Mental Health Systems. 14(1), 1-11 (2020)

4. United Nations, World Youth Report: Youth and the 2030 Agenda for Sustainable Development. [online]. Available at: https://www.un.org/development/desa/youth/world-youth-report/wyr2018.html (2018)

5. OECD, Unemployment rate (indicator) [online]. Available: https://data.oecd.org/unemp/unemploymentrate.htm (2020)

6. World Economic Forum, Disrupting Unemployment Business - led Solutions for Action. [online]. Available at: http://reports.weforum.org/disruptingunemployment/?doing_wp_cron=1607252530.2552969455718994140625 (2015)

7. International Labour Organization, World employment social employment social outlook-trends. [online]. Available at: https://www.ilo.org/global/research/global-reports/weso/2019/lang--en/index.htm (2019)

8. International Labour Organization, Women and men in the informal economy: A statistical picture (third edition). International Labour Office - Geneva. [online]. Available at: https://www.ilo.org/global/publications/books/WCMS_626831/lang--en/index.htm (2018)

9. International Labour Organization, ILO Monitor: COVID-19 and the world of work. Third edition Updated estimates and analysis. [online]. Available at: https:/www.ilo.org/global/topics/coronavirus/impacts-andresponses/WCMS_743146/lang--en/index.htm (2020)

10. International Labour Organization, World Employment and Social Outlook: Trends 2018 (Geneva). [online]. Available at: https://www.ilo.org/wcmsp5/groups/public/---dgreports/---dcomm/--publ/documents/publication/wcms_615594.pdf(2018)

11. International Labour Organization, Global Employment Trends for Youth 2020: Technology and the Future of Jobs. [online]. Available at: https://www.ilo.org/global/publications/books/WCMS_737648/lang-en/index.htm (2020)

12. United Nations, Transforming our world: the 2030 Agenda for Sustainable Development. [online]. Available at: https://sustainabledevelopment.un.org/post2015/transformingourworld (2015)

13. IMFBlog, Chart of the Week: Sub-Saharan Africa's Growth-A Tale of Different Experiences [online]. Available: $\quad$ https://blogs.imf.org/2018/12/13/chart-of-the-week-sub-saharan-africas-growth-a-tale-ofdifferent-experiences/ (2018)

14. World Bank, Promoting rapid economic growth and improving service delivery [online]. Available: https://www.worldbank.org/en/country/ethiopia/overview (2019)

15. AfDB, African Economic Outlook 2019-Macroeconomic Performance and Prospects. [online]. Available at: https://www.icafrica.org/en/knowledge-hub/article/african-economic-outlook-2019-362/ (2019)

16. United Nations, Transforming Ethiopia together. [online]. Available at: https://ethiopia.un.org/sites/default/files/2019-08/Ethiopia_UN_book_\%202018.pdf (2018)

17. F. Zeru, A. Bitga, and J. Boyson, Usaid/Ethiopia Cross-Sectoral Youth Assessment Situational Analysis. [online]. Available at: https://www.youthpower.org/resources/usaidethiopia-cross-sectoral-youthassessment-situational-analysis-report (2018)

18. M. F. Bashir, B. Ma, L. Shahzad, A brief review of socio-economic and environmental impact of Covid-19. Air Quality, Atmosphere \& Health. 13, 1403-1409 (2020)

19. A. Pak, O. A. Adegboye, A. I. Adekunle, K. M. Rahman, E. S. McBryde, D. P. Eisen, Economic Consequences of the COVID-19 Outbreak: the Need for Epidemic Preparedness. Frontier Public Health. 8, $1-4(2020)$

20. IMF, Federal Democratic Republic of Ethiopia: the 2019 Article IV Consultation and Requests for ThreeYear Arrangements Under the Extended Credit Facility and the Extended Fund Facility, IMF Country Report. [online]. Available at: https://www.imf.org/en/Publications/CR/Issues/2020/01/28/The-FederalDemocratic-Republic-of-Ethiopia-2019-Article-IV-Consultation-and-Requests-for-48987 (2020)

21. UNDP, Ethiopia National Human Development Report 2018: Industrialization with a Human Face. [online]. Available http://hdr.undp.org/sites/default/files/ethiopia_national_human_development_report_2018.pdf (2018) 
22. T. Abebe, Lost futures? Educated youth precarity and protests in the Oromia region, Ethiopia. Children's Geographies. 18(6), 584-600 (2020)

23. A. Sumner, C. Hoy, E. Ortiz-Juarez, Estimates of the impact of COVID-19 on global poverty. Unu-Wider. 43, 1-9, (2020)

24. $\mathrm{MOH}, \mathrm{EPHI}$, COVID-19 pandemic preparedness and response in ethiopia; weekly bulletin. [online]. Available at: https://www.ephi.gov.et/images/novel_coronavirus/EPHI_PHEOC_COVID19_Weekly_Bulletin_27_English_11022020.pdf (2020)

25. Z. Shigute, A. D. Mebratie, G. Alemu, A. Bedi, Containing the spread of COVID-19 in Ethiopia. Journal of Global Health. 10(1), 1-4 (2020)

26. V. Erokhin, T. Gao, Impacts of COVID-19 on trade and economic aspects of food security: Evidence from 45 developing countries. International Journal of Environmental Research and Public Health. 17(16), 1-28 (2020)

27. FAO, The state of food security and nutrition in the world 2018: building climate resilience for food security and nutrition. [online]. Available at: http://www.fao.org/3/I9553EN/i9553en.pdf (2018)

28. World Bank Group, Global Economic Prospects. [online]. Available at: https://www.worldbank.org/en/publication/global-economic-prospects (2020).

29. M. R. Breines, Ethnicity across regional boundaries: migration and the politics of inequality in Ethiopia. Journal of Ethnic and Migration Studies. 46(15), 3335-3351 (2020)

30. W. Wondimu, B. Girma, Challenges and silver linings of COVID-19 in Ethiopia -short review. Journal of Multidisciplinary Healthcare. 13, 917-922 (2020)

31. H. F. Kaiser, A second generation little jiffy. Psychometrika. 35(4), 401-415 (1970)

32. H. F. Kaiser, An index of factorial simplicity. Psychometrika. 39(1), 31-36 (1974)

33. R. B. Cattell, The Scree Test For The Number Of Factors. Multivariate Behavioral Research. 1(2), 245-276 (1966)

34. Worldometer, World population. [online]. Available at: www.worldometers.info (2020)

35. EPHI, COVID-19. [online]. Available at: https://COVID19.ephi.gov.et/COVID-19/ (2020) 